\title{
Some Incomes Are Less Average than Others
}

\author{
Silvio Contessi and Ariel Weinberger
}

$\mathrm{T}$ he U.S. economy has experienced sustained trend growth of GDP and a decline in the volatility of macroeconomic variables since the mid-1980s, but has individual real income shared these same trends? Thanks to the increasing availability of individual and household-level data, economists have studied income dispersion and volatility in greater detail. Indeed, many recent studies focus not only on average income, but also on differences within and among groups of individuals (e.g., baby boomers or the top 5 vs. bottom 95 percent of the income distribution). A common finding is that both dispersion between individuals at any point in time and volatility of labor income over time are significantly different across various groups.

This twofold finding prompts two questions. The first is whether income has become more or less dispersed over the years. U.S. data show that the median real wage for all workers grew by 1.4 percent per year between 1995 and 2003, when productivity growth was almost 3 percent per year and the labor share of national income remained flat. Although mean real income has kept pace with productivity growth, various analyses have found a sizable difference between mean and median income. This wedge can be explained by the disproportionate increase in real income in the top 10 percent of the income distribution; as a group, the top earners drive the mean but barely affect the median. Who are these individuals? They are mostly the very best (and rare) "superstars" with sizable wage premia in various occupational niches, particularly in the

top 1 percent of the income distribution. ${ }^{1}$

The second question is whether income volatility has changed over time. Based on the Panel Study on Income Dynamics (a nationally representative panel of U.S. households), average income volatility has increased significantly since the 1970 s. This finding contrasts with other studies based on administrative records on pretax earnings that show small changes. ${ }^{2}$ These two apparently contradictory results can be reconciled by considering that, again, "averages" do not tell the whole story because they neglect heterogeneity among individuals.

A look at different income groups reveals that about 95 percent of the U.S. population experienced minimal or no change in income volatility (see chart). Rather, the rise in average volatility appears to be entirely explained by increased income volatility of individuals who have had the largest income changes in the pastthose at the top end (right tail) of the distribution. ${ }^{3}$ In other words, individuals who experienced a disproportionate past increase in their income continued to experience a disproportionate increase in its volatility. Although we don't know for sure, some of these "volatile" earners could be the aforementioned superstars. Jensen and Shore (2008) observe that increased volatility is more likely among individuals who describe themselves as risk-tolerant and the self-employed, whose income swings are also less likely to appear in administrative data, a fact that might also explain the results of studies using such a data source.

\footnotetext{
${ }^{1}$ Dew-Becker, Ian L. and Gordon, Robert J. "Where Did the Productivity Growth Go? Inflation Dynamics and Distribution of Income." Brooking Papers on Economic Activity, 2005, No. 2, pp. 67-127.

2 Dahl, Molly; DeLeire, Thomas and Jonathan Schwabish. "Trends in Earnings Variability Over the Past 20 Years.” Working Paper, Washington, DC: Congressional Budget Office, April 2007.

${ }^{3}$ Jensen, Shane T. and Shore, Stephen H. "Changes in the Distribution of Income Volatility.” Unpublished manuscript, 2008.
}

\section{Percentiles of Volatility Distribution, Permanent Income Changes 1969-2005}
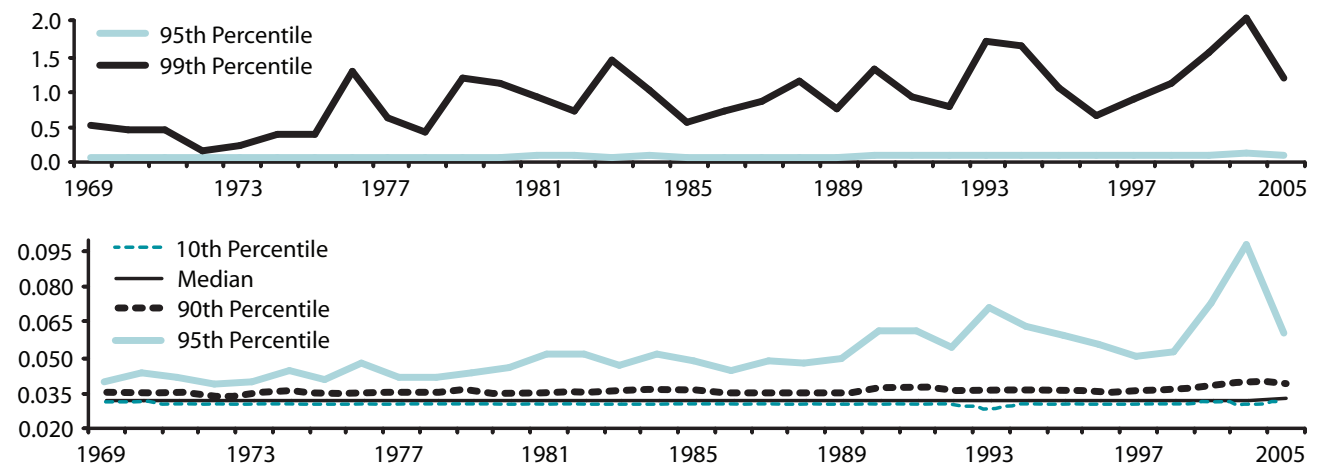

SOURCE: Jensen and Shore (2008). 